\title{
DON VASCO DE QUIROGA PROMOTOR DE LA EDUCACIÓN INDÍGENA
}

\author{
Dr. Fernando Campo del Pozo ${ }^{1}$ \\ Instituto de Historia de la Orden de San Agustín - Venezuela \\ Grupo de Investigación ILAC \\ fernandocampo@picos.com
}

Recepción: 30/05/2008

Evaluación: 30/07/2009

Aceptación: 14/09/2009

Artículo de Reflexión

\section{RESUMEN}

El objeto de este trabajo es resaltar la actuación docente de los agustinos en México, con Vasco de Quiroga, "Tata Vasco"; fundador de pueblos con escuelas y hospitales, un anticipo de lo que luego se llamó "reducciones." Se ha utilizado una metodología analítica, complementaria y evolutiva dentro de la investigación, que desde hace unos 40 años se está realizando para la historia de la Orden de San Agustín en Hispanoamérica, teniendo en cuenta la bibliografía existente y la revisión de los archivos.

El colegio de San Nicolás se mantuvo floreciente durante la colonia y fue la base de la universidad michoacanesa de San Nicolás de Hidalgo. En ese colegio se formaron muchos de los 200 sacerdotes que había en su diócesis, junto otros tantos religiosos, que enseñaban y predicaban el Evangelio en castellano y en las lenguas aborígenes. Fue un destacado promotor de la educación indígena.

Palabras clave: Reducciones, Educación Indígena, Utopía.

\footnotetext{
1 Doctor en Derecho Civil de la Universidad de Zulia - Venezuela, vinculado al Instituto Histórico Agustiniano - IHA y miembro del Grupo de Investigación la Ilustración en América Colonial "ILAC" de la Universidad Pedagógica y Tecnológica de Colombia .
} 


\title{
DON VASCO DE QUIROGA, PROMOTER OF THE INDIGENOUS EDUCATION
}

\author{
Dr. Fernando Campo del Pozo \\ Instituto de Historia de la Orden de San Agustín \\ ILAC Research Group \\ fernandocampo@picos.com
}

\begin{abstract}
This work has been done by investigating Augustinian and Vasco de Quiroga's teaching Work in Mexico. He's still being called "Tata Vasco". He was founder of towns, schools and hospitals in Mexico, which were later called "reducciones".

Vasco de Quiroga was born in Madrigal de las Altas Torres between 1470 and 1479. Being a great jurist and listener, he founded the Santa Fe de la Laguna institution with some Augustinian's help in 1533. He was appointed as Michoacán's Bishop in 1536, where he made a fine wok by founding villages, hospitals and schools such as San Nicolás, first a seminary and college, and later into a university. He Was also a great natives' rights defender and opponent to slavery. His message still appears today in Vasco de Quiroga University's motto: "Teaching by truth", and the same in its mission. It encourages people to believe in Vasco de Quiroga's catholic humanism in order to change society by means of education.

"Tata Vasco" was a pioneer educating native people in Nueva España virreinato. His essay "People with schools and hospitals" seemed to be a utopia. Later, it became a model for "reducciones", followed by Franciscans and Jesuits in Paraguay.
\end{abstract}

Key Words: Reductions, Educating Native People, Utopia. 


\section{INTRODUCCIÓN}

Vasco de Quiroga puso en práctica las Ordenanzas dadas por Isabel la Católica en 1503, junto con otras normas posteriores de 1509, 1511 y las Leyes Nuevas de 1542. Fomentó por primera vez el ensayo de reducciones con pueblos-hospitales y centros de cultura. "Promovió la educación de los aborígenes conforme a la civilización de España, que estaba a la cabeza de Europa con sus universidades." ${ }^{2}$ Deseaba que la cultura y educación cristiana llegara a todos los aborígenes paganos de Méjico. Fomentó también la formación en artes y oficios con la escuela de escultura en Pátzcuaro hacia 1538 a base de la técnica de la "caña de maíz", dando origen a los Cristos denominados "tarascos", que casi no pesan nada y tienen influencias españolas. Esto me llevó a realizar un estudio especial sobre él durante los diez años de residencia en Medina del Campo (1994-2004) y cerca de Madrigal, a donde fui invitado por su Ayuntamiento, para que hablara sobre él, el 24 de noviembre del 2002. Luego me pidió una colaboración el benemérito profesor y gran promotor de la cultura galaico-hispánica, Dr. "Manuel Mourelle de Lema para su revista Galicia en Madrid, ya que Don Vasco de Quiroga y Alonso de la Cárcel tenía raíces gallegas por parte de su padre, como luego veremos." "' Se hace primero una breve biografia para ver luego el primer ensayo de reducción educativa, que desconocían algunos asistentes al 50 Congreso Internacional de Americanistas, el año 2000, en Varsovia. Lo puso de relieve el "profesor mejicano, filósofo y profundo americanista Leopoldo Zea Aguilar." ${ }^{4}$ Se analiza cómo era la reducción o la fundación de pueblos-hospitales y sus escuelas con un mensaje cultural, que se actualiza en la universidad que lleva su nombre desde 1979.

2 El 26 de enero de 1992 tuve la suerte de visitar la ciudad de Pátzcuaro y vi su estatua con indumentaria episcopal en medio de una fuente, que es como el corazón de esa ciudad. Al visitar el lugar donde están sus restos, los aborígenes montaron en guardia, cuando me oyeron decir que sería bueno llevar parte de sus restos para España, concretamente para Madrigal de las Altas Torres, donde había nacido. Buena se armó. Como estaba formando parte de un congreso agustiniano sobre la inculturación en América y andábamos juntos medio centenar de agustinos, en su mayoría españoles, nos encontramos con que llegó a personarse parte del ejército y la policía, con bastantes aborígenes para que no pudiésemos acercarnos y menos tocar el sepulcro. No salía de mi asombro al comprobar el amor y cariño que los de Michoacán y todo Méjico, especialmente los de Pátzcuaro, tienen al Tata Vasco. El fue un gran promotor de la educación y reducción de los aborígenes. Ese día tomé gran admiración y cariño a Vasco de Quiroga, que se relacionó mucho con los agustinos, especialmente con fray Alonso de Veracruz, sobre el que estaba haciendo un estudio especial con relación al matrimonio de los indios y los privilegios de los religiosos.

3 CAMPO DEL POZO, Fernando. (2008): "Don Vasco de Quiroga y sus pueblos-hospitales" en Galicia en Madrid. No. 84, Madrid. Grupo Cultural Galicia en Madrid, pp. 25-33. Se presentó en XXIV Jornadas de Cultura Gallega (Nuestro pasado histórico) el 17 de julio de 2008, en La Coruña, con muy buena acogida. Tanto la conferencia de Madrigal, como el artículo publicado, me han servido de base para este trabajo, junto con los cronistas agustinos y fuentes bibliográficas y documentales, que se citan en las notas y en la bibliografía.

4 ZEA AGUILAR, Leopoldo. (1912-2004): Es considerado como "el filósofo mexicano más universal". El estuvo de profesor en la UNAM, que le tributó un merecido homenaje al cumplir los 60 años de labor docente. Apoyó en Varsovia una observación mía sobre la educación y la primera universidad en México. Le dieron un aplauso masivo. Surgió una buena amistad y dialogamos varias veces sobre fray Alonso de Veracruz y Vasco de Quiroga. Murió el 9 de junio de 2004. Según testimonio de uno de sus nietos, el joven diplomático, Leopoldo López Zea, su maestro, José Gaos, le inculcó la búsqueda de la identidad latinoamericana. 


\section{Nacimiento de Vasco de Quiroga y su Vida en España antes de ir a las Indias}

Don Vasco de Quiroga nació el año 1470 o 1479 en Madrigal de las Altas Torres, donde se conserva aún su casa solariega, y murió anciano a la edad de 95 años, como aparecía en la lápida de su tumba fúnebre con la fecha de 14 de marzo de 1565 y en una placa colocada en la iglesia de Santa Fe de la Laguna en 1737. Otros colocan su nacimiento en 1478 y hasta en 1485, porque afirma el 9 de agosto de 1555 "que es de edad de más de sesenta años." Esto no contradice a la fecha anterior, a no ser que se suponga, como de hecho hace Francisco Martín Hernández, que rondaría entonces los "70 años." Su padre se llamaba Vasco Vázquez de Quiroga y su madre Da María Alonso de la Cárcel, originaria de Arévalo. Tuvo un hermano llamado Alonso y una hermana, llamada Constanza, que profesó en el convento de las Madres Agustinas el 12 de septiembre de 1502, en lo que hoy son ruinas del convento de San Agustín. Su hermano Alonso fue el padre de D. Gaspar de Quiroga, que llegó a ser cardenal arzobispo de Toledo.

"Su padre, D. Vasco Vázquez de Quiroga, era de origen gallego y llegó a ser gobernador del priorazgo de San Juan, al que pertenecía Paradinas, cerca de Bracamonte, y poseedor de haciendas y mayorazgos." ${ }^{\prime 7}$ Este priorazgo de San Juan estuvo vinculado al convento de San Juan de Belvis, en León, cerca de Audanzas, con posesiones en Paradinas de San Juan (Salamanca) que pasaron en 1534 al convento de Ntra. Sra. de Gracia en "Medina del Campo."

Fue bautizado probablemente en la parroquia de San Nicolás, lo mismo que Alonso Fernández, el Tostado, en 1410, e Isabel la Católica en 1451. Para 1470, la reina Isabel ya se había casado con D. Fernando y se estaba construyendo la unidad de España, que tendría su repercusión en las Indias, especialmente en América.

En Madrigal se relacionó y se hizo amigo de D. Juan Tavera, que había nacido en Toro en 1472 y estuvo en Madrigal. Llegó a ser rector de la universidad de Salamanca y presidente del Consejo de Indias. Era sobrino del P. Diego de Deza, dominico, que asesoró a Colón y a los Reyes Católicos en el descubrimiento de las Indias. El mismo Colón afirmó que fue «causa de que sus Altezas hobiesen las Indias» y era «muy adicto de los Quiroga." Se discute si hizo sus estudios de Derecho en Valladolid o en

\footnotetext{
5 ARCHIVO GENERAL DE INDIAS, Patronato, leg. 181, 28; y Audiencia de México, leg. 1647.

6 MARTIN HERNANDEZ, Francisco. (1993): Don Vasco de Quiroga (Protector de los Indios). Salamanca. Universidad Pontificia, p. 31. Puede verse la abundante bibliografia en las pp. 317-337.

7 BIBLIOTECA NACIONAL, Madrid, Ms. 3451-k, 172, f. 170, donde aparece en verso su genealogía.

8 CAMPO DEL POZO, Fernando. (1998): «Convento de Ntra. Sra. de Gracia en Medina del Campo», en Conventos Agustinos, LAZCANO, Rafael, I, Roma, Institutum Historicum Augustinianum, pp. 578-580 y 604-605.

9 MARTIN HERNANDEZ, Op. Cit, pp. 88-102.
} 
Salamanca, probablemente en ésta, a la que se refiere cuando le dijo al agustino Diego de Chaves, su amigo y contrincante a veces, cooperador en el convento y estudio de Tiripetío: «Es tanta la ceguedad de algunos que piensan que saben algo y estudiaron poco en Salamanca." ${ }^{\prime \prime}$ Equivale a lo que se decía en latín: quod natura non dat, Salmantina non prestat: «Lo que no da la naturaleza, no lo presta Salamanca."

Formó parte del cuerpo de letrados que, durante el reinado de los Reyes Católicos, prestó sus buenos servicios en Granada el año 1492 y en Orán, donde aparece actuando como juez en 1525. De vuelta a la península acompañó a la corte del Emperador Carlos $\mathrm{V}$, de Burgos a Madrid, en febrero de 1529. Ese año se pensaba en renovar la Audiencia de Nueva España, dado los desmanes que cometía D. Nuño de Guzmán. Entre los oidores que se mandaron a finales de ese año estaba Vasco de Quiroga, que recibió la orden de la emperatriz Isabel, esposa de Carlos V, mientras se hallaba en Murcia, el 13 de diciembre de 1529. El 30 llegó a Veracruz y el 9 de enero de 1530 a México, donde fue recibido con bastante solemnidad. Sobre la buena actuación de los nuevos oidores, dejó constancia "Bernal Díaz del Castillo, natural de Medina del Campo."11

Cumpliendo con las normas dadas el 12 de julio de 1530, los nuevos oidores tomaron residencia a Guzmán, Matienzo y Delgadillo. Hicieron descripción de las tierras y de los méritos y cualidades de sus moradores. Apoyaron a fray Juan de Zumárraga para que desempeñase el oficio de protector de los indios. Pregonaron que de ahí en adelante no se permitiría hacer esclavos a los indios por ningún motivo. Los nuevos oidores Salmerón, Maldonado, Ceynos y Quiroga informaron a la emperatriz, Da Isabel, el 30 de marzo de 1531, sobre todo lo que sucedía. "Ellos se opusieron a la esclavitud, no permitiendo que se hiciesen esclavos a los indios por ningún motivo en Méjico. Luego intentaron que los indios viviesen políticamente en república cristiana, pasando de la encomienda a la reducción con nuevos pueblos, donde los aborígenes viviesen de su trabajo, en orden con policía y buenas costumbres." ${ }^{12}$

Va a tomar la iniciativa utópica en este ensayo el oidor Vasco de Quiroga, que junto con el oidor Ceynos, se enfrentó al prior de los dominicos a las puertas de la cárcel de Méjico, cuando reclamaba un esclavo de Delgadillo. Le observaron al dicho prior que los dominicos que se gloriaban de austeridad y de proteger a los indios, tenían un monasterio rico con un pueblo encomendado, en el que no se trataba bien a los indios. "Había contradicción entre lo que decían y lo que practicaban algunos dominicos en Méjico."13 Vasco de Quiroga va a poner en práctica a su manera las instrucciones del 12 de julio de 1530, como luego veremos al tratar de su ensayo de

\footnotetext{
${ }^{10}$ Ibídem, pp. 33. El P. Diego de Chaves (su nombre era Diego de Alvarado) fue electo obispo de Michoacán, a la muerte de Vasco de Quiroga. Murió antes de ser consagrado.

11 DIAZ DEL CASTILLO, Bernal. (1983): Historia verdadera de la conquista de Nueva España, cap. 198, México, Ed. Porrúa, p. 536.

12 CASTAÑEDA, Paulino. (1973): "Quiroga, Vasco de" en Diccionario de Historia Eclesiástica ALDEA, Quinquín, MARIN MARTINEZ, Tomás y VIVES GATELL, José, III, Madrid, Instituto Enrique Flórez. Consejo Superior de Investigaciones Científicas, pp. 20392040 , donde pueden verse sus obras y bibliografía, que muy abundante.

13 MARTIN HERNANDEZ, Op. Cit, pp. 73-76.
} 
reducción, nuevo pueblo y hospital, que encomendó a los agustinos en el verano de 1533 al salir hacia Michoacán como visitador. El 24 de junio de 1535 firmó en México su famosa Información en Derecho, impugnando la Real Cédula de 1534 que volvía a permitir la esclavitud de los indios. En su opinión, los aborígenes de México y de las Indias no podían ser sometidos a la esclavitud, porque eran seres libres y súbditos de los Reyes de España. Y que era injusto permitir a los españoles comprar esclavos.

Una de sus mayores aportaciones fue el ensayo utópico de reducción en Santa Fe, que luego se extendió por Michoacán con escuelas-hospitales procurando liberar a los indios de la ignorancia y la miseria para convertirlos en buenos cristianos con una vida decente y digna. Hizo unas Reglas y "Ordenanzas para el Colegio de San Nicolás y para sus Escuelas-Hospitales. "14

\section{Primer Ensayo Utópico de Reducción en Santa Fé Junto a México}

Se entiende por reducción a una especie de misión con un pueblo o pueblos de indígenas convertidos al cristianismo, que viven en forma de república cristiana conforme al espíritu del carisma o Regla de los religiosos evangelizadores. Se plantea en México una cuestión delicada en 1531 y 1532 sobre la solución que debía darse al problema de los indios, con opiniones diferentes entre los oidores. Su nuevo presidente, Sebastián Ramírez de Fuenleal, que era también obispo de Santo Domingo, se inclinaba por mantener a los indios como vasallos y que pagasen tributo a los conquistadores y pobladores, que tenían repartimientos; mientras que el oidor Ceynos optaba porque sólo algunos indios, como una media parte, se diesen en encomienda.

Esto le permitió a Vasco de Quiroga pensar en nuevos pueblos, poniendo en práctica la Utopía de Tomás Moro. Se trata de un pueblo o pueblos con cierta comunidad de bienes, algo que veían bien los aborígenes, con su escuela, hospital e iglesia. Lo que más llamó la atención fue lo del hospital para los enfermos, ancianos y niños. Los hospitales eran más que casas de cura para enfermos, porque tenían también sus almacenes, donde se turnaban por semanas.

El mismo Quiroga dio normas especiales, reglamentando las horas de trabajo, rezo, descanso, etc. Lo que se producía era común y cada uno retiraba lo que necesitaba según el número de la familia. El sobrante se guardaba para el futuro. Unos eran artesanos, otros labradores, etc. Para este fin compró una gran extensión de tierra, a unos $14 \mathrm{Km}$. de México y estableció el pueblo de Santa Fe, el día en que se celebraba la fiesta mayor del Cristo de las Injurias en Madrigal, el año 1532. Estaba en los altos de México, que los aborígenes llamaban Acxochil, por donde pasa un riachuelo. Los indios vivían en casas dispersas por el campo unidas por veredas y con un centro comunitario. Este ensayo lo puso bajo el control de los agustinos, que llegaron en 1533. "Se encargó de esta nueva fundación el P. Alonso de Borja." 15

\footnotetext{
14 Ibídem, pp. 277-296. Su testamento está en las pp. 297-315.
}

15 Ibídem, pp. 88-102. 
La vida del P. Alonso de Borja aparece en la Crónica de fray Juan de Grijalva ${ }^{16}$, que es el primero de los historiadores agustinos, que tratan de Don Vasco de Quiroga, siendo una fuente fundamental, porque era natural de Méjico, hijo de descendientes de los primeros conquistadotes, por lo que tuvo bastante cercanía, según observa el $\mathrm{P}$. Manuel Merino, ${ }^{17}$ que ha hecho un resumen lo que han añadido otros cronistas agustinos, como P. fray Diego de Basalenque ${ }^{18}$ y "fray Matías de Escobar." 19

Estos cronistas me han servido también de fuente, como se ha observado anteriormente, viniendo a repetir casi lo mismo que fray Juan de Grijalva. Resaltan sus virtudes con una orientación apologética y moralizadora añadiendo detalles de la vida de Vasco de Quiroga y su relación con fray Alonso de Veracruz y otros agustinos. Marginan un poco el aspecto educativo, que aquí se tiene más en cuenta. Ambos coinciden en resaltar la importancia, que, tuvo el hospital de Santa Marta, dedicado a la Concepción de Nuestra Señora en Patzcuaro. A su lado se enseñaban artes y oficios y sirvió de modelo a otros hospitales de la diócesis. Ambos relatan también la obra de fray Alonso de Borjas y cómo Vasco de Quiroga colaboró siendo obispo para la fundación de los conventos de Yuripándaro, Cuiseo y Charo, donde se promovió la educación de los indígenas. El P. Manuel Merino añade, después de recopilar los textos de estos cronistas, que el P. Francisco de Borja con el fin de ser útil en Santa Fe, "aprendió la lengua de los indios, a quienes enseñó en los rudimentos de la gramática, enseñó a leer y escribir a los niños, y preparó a otros en el canto y ceremonias para servir en las fiestas de la Iglesia." ${ }^{20}$ Se obligaba a todos los agustinos procedentes de España a conocer una lengua indígena, por lo que se les dejaba escoger el pueblo, donde la aprendían.

Fray Alonso de Borja era natural de Aranda de Duero y viajó en la primera expedición de agustinos Méjico, donde fue destinado en 1533 por el P. Francisco de la Cruz «a fundar convento de su Orden en el pueblo de Santa Fe», como de hecho lo hizo y dedicó a San Agustín, a dos leguas (14 kms.) de México hacia el poniente:

«Se ejercitó en el ministerio de aquellos Indios que, aunque ya estaban convertidos, necesitaban de quien los instruyese y conservase en una vida como religiosa que profesaban. $»^{2 l}$ Vasco de Quiroga fue un admirador y lector de la Utopía de Tomás

\footnotetext{
16 GRIJALVA, Juan de. (1624): Crónica de la Orden de Nuestro Padre San Agustín en la Provincia de Nueva España. Méjico, Imprenta de Juan Ruiz, ff. 198-202.

${ }^{17}$ MERINO, Manuel. (1966): "Don Vasco de Quiroga en los cronistas agustinos", en Missionalia Hispanica. No. 23, Madrid, Instituto Enrique Flórez, Consejo Superior de Investigaciones Científicas, pp. 89-112.

18 BASALENQUE, Diego. (1963): Historia de la Provincia de San Nicolás de Tolentino de Michoacán, de la Orden de N. P. S. Agustín, México, Editorial Jus, pp. 62-67. La primera edición es de 1673.

19 ESCOBAR., Matías de. (1891): Americana Thebaida. Vitas Patrum de los Religiosos Ermitaños de la Provincia de San Nicolás de Tolentino de Michoacán, Morelia Imp. Escuela de Artes, pp. 379-38. Esta obra escrita entre 1740 y 1745.

${ }^{20}$ MERINO, Manuel, Op. Cit, pp. 11-112.

${ }^{21}$ SICARDO, José. (1996): Suplemento crónico a la historia de la Orden de N. P. S. Agustín de México. Introducción y notas por JARAMILLO ESCUTIA, Roberto, México, Col. Cronistas y Escritores. Agustinos de América Latina, 3, ed. OALA, pp. 13-14.
} 
Moro, lo mismo que de la Regla de san Agustín, que exigía vida común como los primeros "cristianos." 22

Este ensayo de reducción fue fruto de una planificación iniciada por Vasco de Quiroga, con cuyas ideas sintonizaba fray Alonso de Borja entre los Otomíes, que se acostumbraron a vivir en vida comunitaria y cuasi monacal, siguiendo las orientaciones de la Regla de San Agustín. Con la ayuda del Licenciado Vasco de Quiroga organizó, al lado del convento, una especie de abadía medieval con un colegio para niños, asilo de ancianos y sementeras comunes para el sostenimiento de las familias que, en 1536, eran unos 37.000 habitantes. Aquellos indios imitaban en algo a los religiosos, convirtiendo las tierras en comunes y ocupándose en la oración y vida más perfecta, semejante a la del tiempo de los Apóstoles. Fray Juan de Grijalva lo relata del modo siguiente:

Había [a] dos leguas de México un pueblo que se llama de Santa Fe, fundado de los indios que, ya convertidos, querían vivir vida más perfecta al modo apostólico y como en vida religiosa, al cual venían los indios de diversas partes con todas sus familias, y eran tantos, que pasaban de doce mil vecinos. Fue autor de este santo instituto el Licenciado Vasco de Quiroga, oidor de la Real Audiencia de México y personaje de gran celo y cristiandad; después fue dignísimo obispo de Michoacán. Este gran varón compró todas aquellas tierras de la redonda de Santa Fe, que son muchas y buenas, y daba destas tierras a los que alli se recogían, para que alli sembrasen y recogiesen lo que parecía ser suficiente para el sustento de sus familias; y que lo restante del tiempo lo gastasen en ejercicios de perfección. De manera que aquellos indios imitaban en algo a los religiosos, viviendo de tierras comunes y ocupándose en oración y vida más perfecta. En amaneciendo se juntaba todo el pueblo y rezaba la doctrina cristiana, decíales la Misa y predicábales todos los días; en acabando, que no era temprano, se iban a sus casas a comer un bocado y luego los que tenían que hacer en su labor se iban a ella, los demás se volvían a la iglesia; unos a de aprender la doctrina, otros a enseñarla; de modo que todos estuviesen ocupados.

A la oración se juntaban todos por barrios en todas las esquinas, donde bahía cruces altas y siempre adornadas de juncias y flores, donde cantaban la doctrina y luego pedían a Nuestro Señor les tuviese de su mano, para que aquella noche no le ofendiesen... De aqui tuvo principio la ceremonia que después se estableció en toda la provincia de cantar la doctrina por barrios, de noche en las esquinas y por la mañana en la iglesia.

Todos los viernes ayunaba todo el pueblo y había disciplina seca en la iglesia a primera noche, después de haber dicho las oraciones... Parecía aquel pueblo convento de religiosos más que república de seglares. ${ }^{23}$

\footnotetext{
22 PREEVOST, Robert F. (2008): Regla y Constituciones de la Orden de San Agustín, Roma, Curia Generalicia, pp. 11, donde aparece el texto de la Regla, cap. 1, n. 3 y de los Hechos de los Apóstoles, 4, 32-35.

${ }^{23}$ GRIJALVA, Juan de. (1624): f. 15, col. 2-3.
} 
La idea utópica se abrió camino en contacto con el topo, la geografía y la psicología del indio con nuevos horizontes y éxitos económicos; pues comenzó con menos de doce mil indígenas imitadores de la perfección religiosa y la cifra se triplicó en cinco años. Se dividían las horas del día entre ejercicios de piedad y el cultivo de las tierras, que todos poseían en común. Se planificaron calles, se construyeron casas decentes y bastante bien iluminadas con ventanas, se canalizaron las aguas para el riego de los campos y las plantaciones, etc. Con el producto, después de dar a cada uno lo que necesitaba, se cubrían los gastos del hospital y colegio, donde se educaban los muchachos. Los mayores podían aprender también a leer y escribir, canto llano, etc. El colegio llegó a convertirse en un verdadero seminario indígena, que hubiese producido sus buenos resultados de no haber abandonado los agustinos esa población para ir a convertir a otros "gentiles en los llanos de Atotonilco, donde se fundó un pueblo con el este nombre en 1536, continuando con otro ensayo parecido." ${ }^{24}$ La vida de estos pueblos o reducciones estaba organizada para enseñar la doctrina cristiana mediante coros en cada barrio, según testimonio del mismo Juan de Grijalva en los siguientes términos:

La doctrina cristiana se enseñaba siempre en los patios de la iglesia, porque como ha de ser tan general para todos, es bien que el lugar sea público. Allí se dividen por los ángulos, a una parte los varones y a otra las hembras, y unos indios viejos, que les enseñan según la necesidad. Solía ser dos horas por la mañana y dos por la tarde, ya parece que bastan las dos horas de por la mañana. Y con este cuidado salen todos muy bien enseñados en la doctrina, en la cual los examinan rigurosamente antes de casarlos y en la cuaresma, cuando les llega el tiempo de las confesiones. En el rezar hay en la Provincia más y menos; porque hay muchos pueblos, donde en las encrucijadas de las calles todas las noches por barrios salen a cantar todos los indios del pueblo no sólo las cuatro oraciones sino muchos himnos, que tienen traducidos en su lengua; y por las mañanas al alba, y los días de fiesta juntos al pie de una cruz, que en cada barrio hay, vienen en procesión a la iglesia los de un barrio cantando estos himnos $v$ oraciones. Este fue el uso antiguo que el santo Fray Alonso de Borja instituyó en Santa Fe y de alli lo imitaron muchos. ${ }^{25}$

Francisco Martín Hernández se sorprende del número y supone que no sería la vida tan comunitaria y perfecta, aunque reconoce el valor de este ensayo como un ideal, que luego procuró poner también en práctica Vasco de Quiroga en Michoacán:

\footnotetext{
${ }^{24}$ SICARDO, José. (1996): Atotonilco significa lugar de aguas calientes: Atl, que significa agua, y totonili, que significa caliente. El mismo fray José Sicardo explica cómo se forma la palabra Atotonilco. p. 32.

${ }^{25}$ GRIJALVA, Juan de. (1624): f. 72, col. 1-2. Cf., JARAMILLO ESCUTIA Roberto. (2002): Huellas Agustinianas. Compendio de Historia de la Orden de San Agustín para América Latina, México, OALA, pp. 100-103; CAMPO DEL POZO, Fernando, (2007): "El modelo universitario agustiniano en América" en Autonomía y Modelos Universitarios en América, SOTO ARANGO, Diana y LAFUENTE GUANTES, María Isabel. León, Universidad de León- RUDECOLOMBIA, pp. 34-35.
} 
Ni los habitantes pasarían de treinta mil, pues apenas si acababa de empezar el pueblo cuando a él llega fray Alonso en 1533; tampoco parece que llevaran todos vida religiosa tan señalada. Sin embargo, algo queda de la descripción: es el ideal de aquella iglesia primitiva que ahora se quiere llevar a la práctica en estas primeras comunidades de cristianos...Será uno de los sueños más acariciados del oidor y después obispo de Michoacán don Vasco de Quiroga. ${ }^{26}$

Con la llegada de un nuevo virrey se instala un nuevo régimen de gobierno con juicio de residencia para los mismos oidores, como Vasco de Quiroga, que también tenía algunos enemigos, como Jerónimo López, ${ }^{27}$ corregidor de la ciudad de México, que no veía bien el ensayo de Vasco de Quiroga. Los agustinos, al ver que aquellos indios estaban evangelizados, decidieron ir a otras regiones como la de Atotonilco en Michoacán, donde los agustinos colaboraron también con Vasco de Quiroga siendo obispo.

\section{Funda Colegios y Hospitales en la Diócesis de Michoacán}

Vasco de Quiroga fue nombrado obispo de Michoacán en 1536 para esta diócesis que había sido erigida el 6 de agosto de 1534 con sede en Tzintzyntzan. Habían renunciado fray Luis de Fuensalida y fray José de Ávila. Lo aceptó Vasco de Quiroga, que necesitaba una preparación, por lo que no fue consagrado hasta 1538, tomando posesión de la diócesis el 6 de agosto. Se estableció primero en la antigua residencia de los caciques michoacanos, trasladándose luego a Páztcuaro, donde erigió en la iglesia de san Francisco de Asís la catedral de la diócesis de Michoacán. Intentó poner en práctica su ensayo de Santa Fe acomodado a las circunstancias con colegios y hospitales, preocupándose también de las artes y oficios, como se ha observado anteriormente.

Junto a la catedral fundó el colegio de San Nicolás en mayo año 1542 y un año después, lo puso bajo la protección y patronato de la Corte para garantizar su subsistencia. Era un colegio de enseñanza para los hijos de españoles, donde estudiaban durante cuatro años latín y ciencias filosóficas y teológicas, como preseminario, para tener luego suficiente clero. Convivían con ellos algunos jóvenes indios, que aprendían el castellano junto con el latín y las ciencias humanísticas. Al mismo tiempo enseñaban la lengua nativa a los hijos de españoles. La enseñanza era gratuita con vida comunitaria y buenos resultados. Aunque en su mente e intención estaba la necesaria y posible ordenación de los indios, no fundó ningún seminario para ellos, ya que había fracasado el ensayo de Tralteloco a cargo de los franciscanos en México. El participó en el segundo concilio de México, donde se estableció en el cap. 9 que «no sean admitidos a los órdenes sagradas los que fueren mestizos, indios y mulatos». Esto se aprobó también en el segundo Concilio de Lima de 1567. El que va fundar un colegio-seminario para hijos de caciques e indios con éxito fue fray Luis López de Solís en Quito en 1594. ${ }^{28}$

\footnotetext{
${ }^{26}$ MARTÍN HERNANDEZ, Francisco. (1993): Don Vasco de Quiroga (Protector de los

Indios). Salamanca. Universidad Pontificia, p. 99.

27 Ibídem, p. 103.

${ }^{28}$ CAMPO DEL POZO, Fernando. (1991): "Los sínodos de fray Luis López de Solís y el 5.

clero indígena," en Archivo Agustiniano. No. 75, Valladolid, pp. 87-114.
} 
Fueron muchas las escuelas y colegios fundados por los agustinos en Méjico siguiendo el ensayo del colegio y hospital que se hizo en Santa Fe, con la ayuda de Vasco de Quiroga y se repitió en Michoacán con bastante éxito. Al lado de cada doctrina y convento funcionaba indefectiblemente una escuela y un hospital, como observa el P. Alipio Ruiz Zavala, que menciona entre los centros propios de los agustinos a «Yuririapúndaro, Cuitzeo, Tacámbaro, Guadalajara, Valladolid, Atotonilco, México, Puebla, Las Habana, Oaxaca, Atlixco, Culhuacán, etc. Aun en lugares tan pequeños como Malinalco, llegaron a establecer estudios de moral y "lenguas indígenas." ${ }^{29}$

Este ensayo lo pusieron en práctica algunos franciscanos y los jesuitas en el Paraguay, Fray Agustín de Coruña lo intentó introducir en el Nuevo Reino de Granada, al ser nombrado Obispo de Popayán, donde compuso algunos cánticos para los indios. Se preparó con este fin a los doctrineros agustinos en el convento de San Agustín de Quito con el colegio de San Nicolás, donde se formaron algunos de los doctrineros que evangelizaron a Venezuela a finales del siglo XVI y comienzos del XVII, porque los conventos y doctrinas de Venezuela dependieron de la provincia de San Miguel de Quito. En algunas haciendas de los agustinos como la de Otengá, Ntra. Sra. de Belén de Chámeza y Ntra. Sra. de Chiquinquirá de Río de Oro se puso en práctica, quedando pueblos en su lugar con el mismo nombre. Algo parecido ha sucedido en el Perú, Ecuador, etc. En Venezuela se puso en práctica en la misión y reducción de Aricagua, Estado Mérida, desde finales del siglo XVI hasta el siglo XIX.

Vasco de Quiroga estuvo en España desde 1546 hasta 1554 para tratar asuntos importantes de su obispado y apoyar la fundación de la universidad de México. Pensó acudir al Concilio de Trento y nombró como encargado de la diócesis a fray Alonso de Veracruz. Estuvo en España ocho años arreglando problemas de su diócesis y de los aborígenes. El 23 de abril de 1553 escribe su carta De debellandis indis, donde admitía en algunos casos el derecho a la guerra «con los indios que estaban por allanar»o estaban en guerra como los chichimecas, vecinos de los de Michoacán. Este era un problema delicado ${ }^{30}$. Seguía la doctrina del llamado "agustinismo político" con apoyatura en san Agustín y en algunos Papas para defenderse y evangelizar, como opinaba también fray Alonso de Veracruz. Esto se justificaba en aquella época. Fray Alonso de Veracruz renunció por tres veces al episcopado para defender más libremente los derechos de los aborígenes y los privilegios de los religiosos.

\section{Muerte de Vasco de Quiroga y su Labor como Obispo de Michoacán}

Murió el día 14 de marzo de 1565 en Uruapán, mientras hacía una visita pastoral,

\footnotetext{
29 RUIZ ZAVALA, Alipio. (1984): Historia de la provincia agustiniana del Santísimo Nombre de Jesús de México, 1, México, Ed. Porrúa, p. 406. Es ratificado esto por JARAMILLO, Roberto. (1991): Los Agustinos de Michoacán, 1602-1652. La dificil formación de una provincia, México, Orden de San Agustín, pp. 23, 27 y 275; CAMPO DEL POZO, Fernando. (2007): El modelo universitario agustiniano en América, pp. 35-39.

${ }^{30}$ RUIZ ZAVALA, Alipio. (1984): El tema era muy discutido después de las Leyes nuevas de 1542. pp. 176-180.
} 
con 95 años, según la leyenda que aparece en la Iglesia de Santa Fe de México ${ }^{31}$. Sus restos mortales se llevaron a Pátzcuaro, donde se hizo el inventario de sus bienes el 20 de marzo. Fue enterrado en la catedral. Al trasladarse la sede de la diócesis en 1580 a Valladolid (Morelia), se quiso llevar sus restos; pero se opusieron decididamente los de Pátzcuaro, que le debían mucho, porque como afirmó fray Diego de Basalenque, además de fundar el Hospital de Santa Marta dedicado a la Concepción con sus escuelas de artes y oficios, "en este pueblo y composición de su policía vivió el Obispo Don Vasco de Quiroga veinticinco años, habiendo entrado de setenta, de modo que pasó largamente de los noventa años a recibir el premio que tan buen Obispo merecía." ${ }^{32}$

Como obispo, Vasco Quiroga visitó pastoralmente su diócesis, reformó la clerecía, y estableció el primer pre-seminario de América con su colegio de San Nicolás de Bari o Mira, que le recordaba al patrón de la universidad de Valladolid y al titular de la principal iglesia de su pueblo natal. Se enfrentó a caciques, hacendados y encomenderos colaborando con los agustinos hasta llegar a más de los 90 años con un espíritu paternal, por lo que nunca le llamaron sus súbditos "ilustrísimo señor", sino que le llamaban y le siguen llamando con cariño y sencillamente el "Tata Vasco". Fue muy devoto de la Eucaristía y de la Santísima Virgen.

El se acordó de la villa de Madrigal, donde nació, especialmente de la iglesia de San Nicolás, donde estaban enterrados sus padres y debían decirse 12 misas de aniversario con vigilia. Y se debía poner la alfombra sobre la tumba. Sus hospitales debían dar 50 ducados. Se hace referencia a una posible capilla en la Iglesia de San Nicolás y en Nuestra Señora del Castillo, etc. Debían hacerse sufragios por él y también por sus familiares y bienhechores difuntos en la catedral de Michoacán. ${ }^{33}$ Se le recuerda con una placa y pancarta en delante de la iglesia de Santa Fe de México con estas palabras:

Visitante:

Esta Comunidad te saluda para honrar su historia. En la época prehispánica, este lomerío era conocido como Acaxochiltl (lugar donde hay cañas de flor). Se funda el primer Pueblo Hospital (utópico sueño de Tomás Moro) en 1532-1537.

Lo funda Don Vasco de Quiroga, conteniendo este espacio el hospital, la rectoría, la Casa de Niños expósitos (Obra precursora de la Seguridad Social en América). Pueblo Hospital que perteneció al Obispado de Michoacán hasta el 2 de enero de 1872. Gobernado por las Reglas y Ordenanzas que dejó su Fundador para los hospitales de Santa Fe de México y Michoacán

\footnotetext{
31 Dice la leyenda: "Obit in Civitate de Pascuaro anno Domini 1565 aetatis suae 95". Se puso esta inscripción en 1737. Como de hecho no murió en Pátzcuaro sino en Uruapán, es posible que no sea correcta la edad que se le atribuye. Cf. MARTIN HERNANDEZ, Francisco. (1993): Pasó de los noventa años. pp. 259-260.

32 BASALENQUE, Op. Cit, pp. 214-216.

${ }^{33}$ AGI, Justicia, 208, donde se encuentra el Testamento-memoria publicado por MARTIN HERNANDEZ, Francisco. (1993): pp. 296-315.
} 
Fernando Campo del Pozo

En la fachada interior del muro, junto a la puerta de la catedral de Pátzcuaro está el himno del Tata Vasco en purépecho, que en castellano dice así:

Gloria y honor, Tata Vasco, son para ti, con tu gloria, diste fe, diste amor a mi patria, y este Michoacán es testigo que fuiste ternura y gran bondad. A Morelos las clases tú le diste, Señor. Diste luz a las antorchas de ayer. Derramaste tu valor y la patria te premia y te da su amor. Fuiste clarín celestial de grandeza, a mi traza diste fortaleza. Que vivas glorioso te dice Michoacán. ${ }^{34}$

Esto se recuerda también en Madrigal, su cuna natal, donde los mexicanos han colaborado para un llamativo y modesto monumento en 1970, cuando se creía que se estaba celebrando el V Centenario de su nacimiento con esta inscripción:

Aquí nació d. Vasco de Quiroga Primer obispo de Michoacán Padre de los indios Fundador de pueblos y de aulas Experto en leyes y en gobierno Precursor de la seguridad social en caridad y persuasión eximio A su memoria en el $v$ centenario de su natalicio México erige este monumento año 1970.35

\section{Universidad Vasco de Quiroga que Recuerda su Memoria}

El 1 de enero de 1979 se fundó la Universidad Vasco de Quiroga, como privada y de inspiración cristiana, conforme al ideario espiritual del primer obispo de Michoacán. Surgió con un Patronato para la Educación Superior de Michoacán, para complementar a la educación pública de este estado en el antiguo edificio de secundaria denominado fray Alonso de Veracruz, que cedieron los agustinos en Morelia para convertirse en el primer campus Santo Tomás Moro con el nombre de Estudios Superiores Vasco de Quiroga A.C., con un estilo especial de enseñanza y libertad de cátedra. Su lema es educar en la verdad y su misión formar personas íntegramente, inspirados en el humanismo católico de Don Vasco de Quiroga para que sean agentes de cambio de la sociedad. ${ }^{36}$

En 1980 se inicia un crecimiento prometedor, al inaugurarse su preparatoria y en 1982 se abre la escuela de Arquitectura y en 1990 se inauguran las facultades de Ciencias de Comunicación y Sistema Computacionales, a las que siguen las licenciaturas de Contaduría Pública y Administración de Empresas, expandiéndose con dos nuevos campus en Tocámbaro y Ciudad Hidalgo, ofertando Maestría en Administración En 1992 se inauguró el primer edificio, que es actualmente su Alma Mater, el campus Santa María y tres años después se oferta el Doctorado en Psicoterapia Familiar, consolidándose esta institución, como universidad privada para 5.000 alumnos y unos 800 catedráticos, ampliando a Diseño Gráfico, Comercio internacional, Nutrición, Derecho, Filosofía.

\footnotetext{
${ }^{34}$ Ibídem, p 123.

35 Ibídem, p 140.

${ }^{36}$ KELLY, Jhon J. (2004): The Catholic University of Havana, Miami, Florida, Rodes Printing, p. 92. La historia de estas universidades está en parte sin hacer. Sus locales han sido utilizados para distintos fines. Queda la estatua de Santo Tomás de Villanueva sin cabeza a la entrada de la universidad.
} 
Se ha complementado lo que había estado monopolizado por la Universidad Michoacana de San Nicolás de Hidalgo, que recordaba el centro fundado por el "Tata Vasco": pero se necesitaba un centro que siguiese más fielmente el ideario cristiano y el pensamiento con la orientación católica y un humanismo según el primer obispo de Michoacán. Desde México fueron los agustinos a Filipinas, donde se fundó la Universidad de San Agustín en Iloilo, donde sigue con más de 10.000 alumnos. En la Habana se fundó la Universidad de Santo Tomás de Villanueva, que fue clausurada por el régimen de Fidel Castro en 1960.

\section{Estado Actual de su Proceso de Canonización}

Se inició el proceso de canonización, con una solemne apertura, el 10 de noviembre de 1997, en la basílica de Ntra. Sra. de Pátzcuaro y en 2004 se nombró de postulador al P. Salvador Vázquez, que lleva la causa bastante adelantada y se espera su pronta conclusión.

Vasco de Quiroga tuvo enfrentamientos con algunos dominicos y oidores; pero de hecho está recibiendo cierto culto y veneración en Patzcuaro, en todo Michoacán y México, donde le empiezan a conocer los mejicanos desde niños al aparecer en los libros de texto de Historia. La obra de Vasco de Quiroga subsiste aún en México, donde es más conocido y admirado que en su patria chica. Los mejicanos han colaborado no sólo para la colocación de su busto, sino también para el museo dedicado a su memoria, que llaman la atención de los turistas en el "Real Hospital de Madrigal." ${ }^{37}$

Conviene recordar que las relaciones de Vasco de Quiroga fueron buenas y cordiales con sus súbditos y el clero, en general, por lo que los cronistas agustinos tienen para él muchos elogios, como ha puesto de relieve el P. Manuel Merino, recordando que Don Vasco de Quiroga y Andrés de Urdaneta se vieron varias veces, especialmente cuando tenía el cargo de Visitador de Corregimientos conferido por el virrey Mendoza. Los agustinos, siendo pocos al principio, le cedieron al P. Alonso de Borja a Vasco de Quiroga, porque tenía los mismos ideales y estuvo cuatro años al cuidado del hospital, catequesis, escuelas de leer y escribir, de cantar, tañer y oficios mecánicos, sirviendo de modelo a otros pueblos de su diócesis, donde se reconoce y recuerda su labor "evangelizadora y cultural, enseñando a leer y a escribir con buen método y calma." 38

Esto ya lo puso de relieve el P. Mariano Cuevas cuando afirma sobre el ensayo de Santa Fe lo siguiente: "Congregar tantos indígenas, comprarles terrenos y construir en ellos, hacerles reglamentos tan admirables: son obra y monumento del gran Quiroga. Por tres largos siglos estuvieron en plena florescencia, y aun a través de un largo siglo

37 ZURRO MANSO, Firmo y CERRO CALVO, Ester. (1996): Madrigal de las Altas Torres. Recuerdos para la historia. Madrigal de las Altas Torres, Ávila, Ayuntamiento de Madrigal, pp. 107-110.

38 MERINO, Manuel. (1966): pp. 110-112, donde se recogen los informes de otros historiadores extraños que han tratado de la amistad y relación de los agustinos con Vasco de Quiroga. Su relación con los agustinos se puso de relieve al dar una charla en Madrigal de las Altas Torres el día 24 de noviembre del 2002. 
de persecución, quedaron algunas huellas vivas hasta nuestros días en los hospitales que, con el nombre de Santa Fe, construyó en las cercanías de México y en las del lago de Pátzcuaro. Fue grande, repetimos, el mérito del señor Obispo Quiroga: pero también fue grande el de los primeros Agustinos, quienes, no obstante ser tan pocos, cedieron a uno de ellos, el P. Alonso de Borja, quien tenía a su cargo los ideales de Quiroga y el trato cercano con aquellas primitivas semimontaraces indianas. Allí se estuvo cuatro años cuidando del hospital, catequesis, escuelas de leer y escribir, de cantar y de tañer y e varios oficios mecánicos" 39 .

El mismo Mariano Cuevas pone como modelo a la reducción hecha en Michoacán por los agustinos, "que todo lo llevaron desde el principio con método y calma. Fundaron al mismo tiempo una escuela y un hospital que sirvió de modelo a los que puso Vasco de Quiroga en los pueblos pequeños de su Diócesis"40.

Vasco de Quiroga murió el mismo año en que fray Andrés de Urdaneta descubría la ruta de vuelta de las Islas Filipinas a Méjico, que surcó durante dos siglos un famoso Galeón con el nombre del Santo Niño de Cebú, estableciendo relaciones comerciales y religiosas. "Entre ambos hubo algún trato y buenas relaciones"41. Don Vasco de Quiroga es uno de los representantes más conspicuos de España en Méjico con repercusión importante por sus escritos de Doctrina para los Indios y Sermones, Reglas y Ordenanzas para el gobierno de los hospitales de Santa Fe, México y Michoacán. Es digno de estar en los altares. Con algunos años de retraso se cumple un deseo del P. Constantino Bayle, buen historiador de Vasco de Quiroga cuando afirmó en 1950: "No lo llamamos hoy San Vasco más propiamente no se lo llama la Iglesia, que sí los indios - por faltar quien promueva su causa: la opinión de su santidad no queda en zaga a la de nadie entre sus contemporáneos. Y el amor que los indios le tuvieron, sin par; aun hoy para ellos nuestro Tata Vasco, - nuestros Padre Don Vasco, que cuatro siglos no han bastado a "borrar su memoria" 42 .

El mismo observó también que para conocer y estudiar a fondo la figura de Vasco de Quiroga, eximio apóstol y misionero, es preciso, además de las historias generales de Nueva España, acudir a las crónicas de la Orden de San Agustín de Méjico, con la cual se halla "estrechamente vinculado" 4 .

Eso hay que hacerlo para comprobar que Vasco de Quiroga fue un promotor de la educación indígena y, junto con fray Alonso de Veracruz, un impulsor de la fundación de la Universidad de Méjico, a la que pronto fueron los aborígenes y mestizos, como puse de relieve en el 50 Congreso Internacional de Americanistas el año 2000 y me apoyó el querido y llorado amigo D. Leopoldo Zea Aguilar. El sabía que fray Alonso de Veracruz, cofundador de la Universidad de México, donde tiene su busto, había llevado

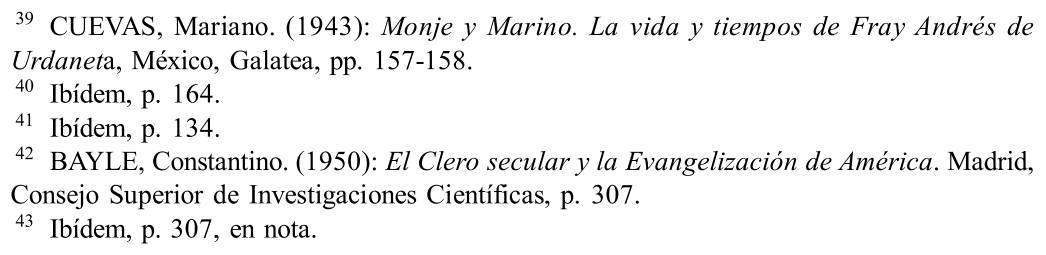


sesenta cajones se libros para organizar la Biblioteca del Colegio de San Pablo, a los que "fue añadido este gran varón todos aquellos que venían a su noticia y no estaban en la librería." ${ }^{44}$ Este era una especie de Colegio Mayor Universitario, razón por la cual los agustinos no fundaron una "universidad en México." 45

\section{CONCLUSIONES}

Gracias a la colaboración de Vasco de Quiroga fueron muchas las escuelas, colegios y hospitales fundados por él y por los agustinos a mediados del siglo XVI en Méjico. El ensayo del colegio y hospital de Santa Fe se repitió en Michoacán y en otras partes con éxito. Al lado de cada doctrina y convento funcionaba una escuela y un hospital. Los pueblos con colegios-hospitales de Vasco de Quiroga fueron las primeras reducciones y una especie incipiente de seguridad social. Lo pusieron en práctica los agustinos en el Nuevo Reino de Granada, especialmente en los pueblos de Aricagua, Muchuchíes y otros del Estado Mérida (Venezuela). Algo parecido se hizo en Otengá, Belén de Chamela y Río de Oro (Colombia). El fundó doctrinas y curatos que fueron la base de muchos pueblos que han llegado a ser florecientes como Indaparapeo, Huaniqueo, Copandaro, Zamora, Guadalajara, Salamanca y su hospital, etc. Era fundamental la escuela y el hospital con vida cuasi-comunitaria.

Como lector de la Utopía del político y escritor Tomás Moro quiso poner en práctica su ideario con el pueblo-hospital de Santa Fé en las afueras de México y otros en Pátztcuaro. Su ensayo de reducciones que parecían una "utopía" como proyecto para realizar, tuvo sus continuadores por los agustinos, franciscanos y jesuitas. Condenó la esclavitud en su Información en Derecho. Sus escritos fueron y siguen siendo aleccionadores. Por esto y por sus obras, junto con una vida santa se merece un puesto en los altares, por lo que se está llevando adelante su proceso de canonización. Se han trascrito 37 expedientes, que ocupan 18.000 folios, a los que hay que añadir los testimonios de muchos cronistas e historiadores. Las Actas del Proceso de Canonización serán en el futuro la mejor fuente para hacer su biografía y demostrar que fue promotor de la educación indígena y de su acceso a los estudios superiores y universitarios.

\footnotetext{
${ }^{44}$ GRIJALVA, Juan de. (1624) f, 153v.

45 CAMPO DEL POZO, Fernando. (2007): "El modelo universitario agustiniano en América" en Autonomía y Modelos Universitarios en América, SOTO ARANGO, Diana y LAFUENTE GUANTES, María Isabel, León, Universidad de León, RUDECOLOMBIA, pp. 36-39.
} 


\section{FUENTES}

\section{ARCHIVO \\ ARCHIVO GENERAL DE INDIAS}

ARCHIVO GENERAL DE INDIAS, Patronato, leg. 181, 28; y Audiencia de México, leg. 1647.

ARCHIVO GENERAL DE INDIAS, Justicia, 208, donde se encuentra el Testamentomemoria publicado por MARTIN HERNANDEZ, Francisco. (1993): pp. 296-315.

Biblioteca Nacional, Madrid, Ms. 3451-k, 172, f. 170, donde aparece en verso su genealogía.

\section{SELECCIÓN BIBLIOGRÁFICA}

BASALENQUE, Diego de. (1963): Historia de la Provincia de San Nicolás de Tolentino de Michoacán, de la Orden de N. P. S. Agustín, México, Editorial Jus. Primera edición 1673.

BAYLE, Constantino. (1950): El Clero secular y la Evangelización de América. Madrid, Consejo Superior de Investigaciones Científicas.

CAMPO DEL POZO, Fernando. (1991): "Los sínodos de fray Luis López de Solís y el clero indígena," en Archivo Agustiniano. No. 75, Valladolid.

. (2008): "Don Vasco de Quiroga y sus pueblos hospitales" en Galicia en Madrid. No. 84, Madrid. Grupo Cultural Galicia en Madrid.

CASTATAÑEDA, Paulino. (1973): "Quiroga, Vasco de" en Diccionario de Historia Eclesiástica. ALDEA, Quinquín, MARIN MARTINEZ, Tomás y VIVES GATELL, José, III, Madrid, Instituto Enrique Flórez. Consejo Superior de Investigaciones Científicas.

CUEVAS, Mariano. (1943): Monje y Marino. La vida y tiempos de Fray Andrés de Urdaneta, México, Galatea.

DIAZ DEL CASTILLO, Bernal. (1983): Historia verdadera de la conquista de Nueva España, cap. 198, México, Porrúa.

ESCOBAR., Matías de. (1891): Americana Thebaida. Vitas Patrum de los Religiosos Ermitaños de la Provincia de San Nicolás de Tolentino de Michoacán, Morelia Imp. Escuela de Artes.

GRIJALVA, Juan de. (1624): Crónica de la Orden de Nuestro Padre San Agustín en la Provincia de Nueva España. México, Imprenta de Juan Ruiz.

JARAMILLO ESCUTIA, Roberto. (2002): Huellas agustinianas. Compendio de Historia 
de la Orden de San Agustín para América Latina. México, OALA.

JARAMILLO ESCUTIA, Roberto. (1991): Los Agustinos de Michoacán, 1602-1652. La dificil formación de una provincia, México, Orden de San Agustín,

MARTÍN HERNANDEZ, Francisco. (1993): Don Vasco de Quiroga (Protector de los Indios). Salamanca. Universidad Pontificia.

MERINO, Manuel. (1966): “Don Vasco de Quiroga en los cronistas agustinos” en Missionalia Hispanica. No. 23, Madrid, Instituto Enrique Flórez, Consejo Superior de Investigaciones Científicas.

RUIZ ZAVALA, Alipio. (1984): Historia de la provincia agustiniana del Santísimo Nombre de Jesús de México, México, Ed. Porrúa.

ZURRO MANSO, Firmo y CERRO CALVO, Ester. (1996): Madrigal de las Altas Torres. Recuerdos para la historia.

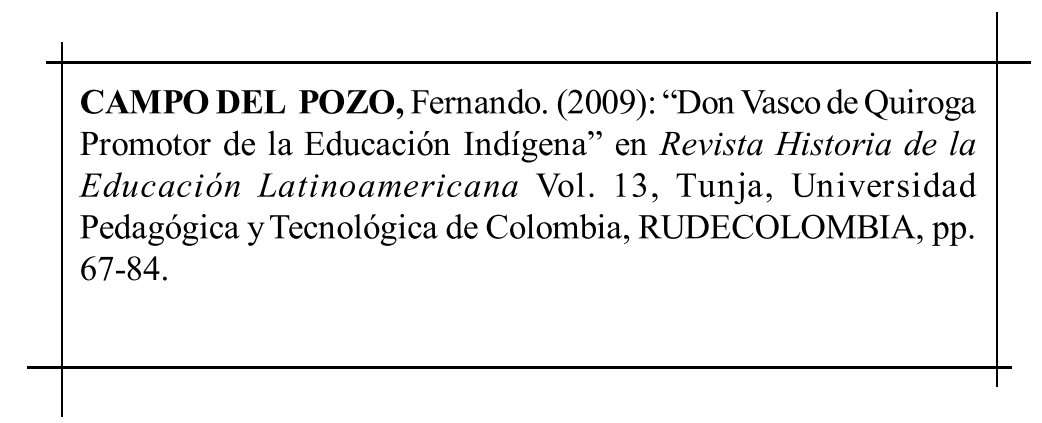

Rhela. Vol. 13. Año 2009, pp. $67-84$ 